\title{
Los polacos en los nuevos flujos inmigratorios en España: una aceptación social diferente
}

\author{
M. - Pilar González Yancl* y M. a José Aguilera Arilla*
}

\section{RESUMEN}

La situación económica, que comienza tras la crisis de 1973, origina grandes cambios en los flujos migratorios internacionales (España reduce su volumen de emigrantes, comienzan a volver los que salieron; los países europeos cierran sus fronteras y favorecen asimismo los retornos). La caída del muro de Berlín en 1989 produce otras novedades (los paises del Este ven aumentar sus flujos de emigrantes, sobre todo hacia Alemania, aunque en menor proporción de la esperada). En estos años, 1979-1997, España, país ya democrático y con una situación económica en alza, se convierte en un país de inmigración. Llegan nuevos flujos con un importante volumen de población: norteafricanos, centroamericanos y europeos orientales. Entre estos últimos, destacan por su proporción los polacos. Este grupo, pese a su carácter económico, es percibido por la sociedad española, que está cambiando su postura ante la inmigración, como uno de los mejor integrados.

\section{INTRODUCCIÓN}

A lo largo de la historia la movilidad de la población es una constante, si bien los flujos han experimentado, de unos períodos a otros, cambios muy notables en dirección, sentido e intensidad. Recientemente, y en concreto desde el inicio de la década de los años ochenta, estamos asistiendo a importantes transformaciones en todo el mundo, algunas de las cua-

* UNED. Madrid. 
les afectan de manera especial al ámbito europeo. Dentro de éste un caso particular es el relacionado con los movimientos que tienen como escenario los países mediterráneos, donde dichas transformaciones han tenido especial importancia.

El caso español es bien significativo. Aunque a lo largo de la historia la Península lbérica ha sido un crisol de culturas de las más variadas procedencias, acogiendo a multitud de pueblos, en los últimos siglos su papel, en el conjunto mundial, ha sido de país emisor de población, con una variada evolución en las características y destinos de sus emigrantes. En cambio, hoy es sabido que España entra a formar parte de los países receptores de inmigrantes.

En este artículo vamos a tratar de cómo esta nueva situación tiene repercusiones en los comportamientos de la población española ante los recién llegados, manifestándose claras diferencias según los casos. Nos centramos para ello en el estudio de los inmigrantes polacos, uno de los grupos mejor acogidos de los nuevos flujos inmigratorios.

\section{LOS CAMBIOS EN LA POSICIÓN DE ESPAÑA EN LOS MOVIMIENTOS MIGRATORIOS}

Al inicio de la década de los años setenta (con la crisis de 1973) comienzan a manifestarse cambios importantes en relación a las migraciones. Por una parte, la emigración experimenta un declive muy notable (cuadro 1), incluso se inicia un proceso de retorno de los que emigraron en el «boom» de salidas a Europa del período del desarrollismo español (de 1975 a 1984 retornan 415.400 españoles según las bajas consulares registradas, que, como es sabido, no recogen a la totalidad). Por otra parte, comienza a cobrar fuerza el movimiento inmigratorio hacia nuestro país, al tiempo que se produce una diversificación de las nacionalidades de los que llegan.

Hasta estas fechas la población extranjera residente en España estaba compuesta por un discreto grupo (un $0,6 \%$ del total de la población en 1971). En él predominaban europeos occidentales, norteamericanos y latinoamericanos, llegados a España con distintas motivaciones, entre las que no abundaban las propias del inmigrante meramente económico ${ }^{1}$.

Desde que Ravenstein enunciara sus famosas leyes, hace más de cien años, se considera que el principal desencadenante de toda migración es el factor económico. No obstante, cuando 
CUADRO 1. EVOLUCIÓN DE LA EMIGRACIÓN ESPAÑOLA 1900-1995*

\begin{tabular}{cccc}
\hline AÑO & N. ${ }^{\circ}$ EMIGRANTES & AÑO & N..$^{\circ}$ EMIGRANTES \\
\hline 1900 & 396.183 & 1950 & 191.075 \\
1905 & 348.910 & 1955 & 379.089 \\
1910 & 713.055 & 1960 & 269.950 \\
1915 & 818.486 & 1965 & 518.873 \\
1920 & 453.878 & 1970 & 400.280 \\
1925 & 484.115 & 1975 & 412.039 \\
1930 & 376.340 & 1980 & 80.251 \\
1935 & 212.598 & 1985 & 115.995 \\
1940 & 33.099 & 1990 & 78.925 \\
1945 & 66.242 & 1994 & 20.850 \\
\hline
\end{tabular}

Fuente: M. ${ }^{\circ}$ Asuntos Sociales. Dirección General de Mıgraciones.

* Datos del periodo.

La década de los años ochenta marca el inicio de una nueva etapa en la que se empieza a considerar a España como país receptor de emigrantes, fenómeno que se da simultáneamente en otros países del norte del Mediterráneo, que experimentan una evolución similar (Italia, Grecia).

Múltiples circunstancias confluyen en la transformación que experimenta España. En los países europeos, que acogían el mayor volumen de inmigrantes del sur (entre otras procedencias de la propia España), comienzan a ponerse trabas a la entrada de nuevos contingentes, e, incluso, se favorece el retorno a los países de origen de los que allí vivían. Simultáneamente, en España comienza una notable mejoría económica, que, unida a determinados cambios políticos (democracia) y demográficos (descenso de natalidad), a la falta de legislación en materia de inmigración (la llamada ley de extranjería data de 1985), además de a la existencia de una notable economia sumergida, favorecen que se desvien hacia el nuestro los trabajadores de países en desarrollo en busca de empleo, al ver dificultado su acceso a los lugares de acogida tradicional.

hablamos de "migrante económico" nos referimos al ligado al capitalismo metropolitano, al que surge en este siglo vinculado a las áreas más industrializadas del planeta. Vid "los inmigrantes en España". Revista de Estudios Sociales y de Sociología Aplicada n. ${ }^{\circ} 661987$ p. 42 . Los extranjeros en España en esta etapa estaban relacionados con motivaciones variadas, politicas, convenios internacionales, etc. 
No obstante, conviene hacer alguna matización. La abundante bibliografía que se ha generado en torno al tema de la nueva situación inmigratoria española, podría hacer pensar que el fenómeno tiene unas proporciones similares a las que tuvo la emigración de españoles en el pasado, o a las que tiene, en la actualidad, la inmigración en otros países occidentales. En realidad, las cifras son aún discretas, pero sin embargo, es fundamental el hecho de que se haya producido el cambio de sentido de las migraciones, que confiere a la actual situación un carácter de "experiencia nueva", más que el volumen en sí de los extranjeros que acuden a nuestro país. Entre 1960 y 1994 la proporción de residentes extranjeros respecto al total de población española pasó de ser el 0,2 al 1,6\% (LÓPEZ DE LERA, D., 1994).

\section{CUADRO 2. EVOLUCIÓN DE LAS CIFRAS DE EXTRANJEROS RESIDENTES EN ESPAÑA}

\begin{tabular}{rrrrrrrrrrrr}
\hline AÑO & EUROPA & $\%$ & AMÉRICA & $\%$ & ÁFRICA & $\%$ & ASIA & $\%$ & OCEANÍA & $\%$ & TOTAL \\
\hline 1975 & 102.702 & 62,1 & 48.142 & 29,1 & 3.232 & 2,0 & 9.393 & 5,7 & 440 & 0,2 & 165.289 \\
1976 & 99.446 & 63,0 & 44.615 & 28,2 & 3.091 & 2,0 & 9.206 & 5,8 & 424 & 0,3 & 157.973 \\
1977 & 102.429 & 63,4 & 45.284 & 28,0 & 3.034 & 1,9 & 9.060 & 5,6 & 433 & 0,3 & 161.451 \\
1978 & 102.501 & 64,7 & 42.840 & 27,0 & 2.908 & 1,8 & 4.485 & 2,8 & 449 & 0,3 & 158.349 \\
1979 & 110.739 & 64,0 & 46.569 & 26,9 & 3.530 & 2,0 & 10.489 & 6,1 & 473 & 0,3 & 173.043 \\
1980 & 118.372 & 65,0 & 46.701 & 25,6 & 4.067 & 2,2 & 11.419 & 6,3 & 518 & 0,3 & 182.045 \\
1981 & 130.292 & 65,8 & 47.597 & 24,0 & 5.013 & 2,5 & 13.554 & 6,8 & 595 & 0,3 & 197.942 \\
1982 & 133.338 & 66,4 & 46.285 & 23,0 & 5.405 & 2,7 & 14.389 & 7,2 & 627 & 0,3 & 200.911 \\
1983 & 140.095 & 66,6 & 46.603 & 22,2 & 5.982 & 2,8 & 15.987 & 7,6 & 689 & 0,3 & 210.350 \\
1984 & 148.944 & 65,8 & 50.344 & 22,2 & 7.668 & 3,4 & 17.767 & 7,8 & 715 & 0,3 & 226.470 \\
1985 & 158.126 & 65,3 & 54.067 & 22,3 & 8.529 & 3,5 & 19.451 & 8,0 & 748 & 0,3 & 241.971 \\
1986 & 188.450 & 64,3 & 64.698 & 22,1 & 14.135 & 4,8 & 24.007 & 8,2 & 845 & 0,3 & 293.208 \\
1987 & 216.078 & 64,5 & 71.615 & 21,4 & 18.543 & 5,5 & 26.544 & 7,9 & 945 & 0,3 & 334.936 \\
1988 & 234.000 & 65,0 & 75.392 & 20,9 & 20.068 & 5,6 & 28.282 & 7,9 & 1.029 & 0,3 & 360.032 \\
1989 & 259.474 & 65,2 & 83.397 & 20,9 & 23.712 & 6,0 & 28.938 & 7,3 & 1.236 & 0,3 & 398.147 \\
1990 & 270.022 & 66,4 & 80.558 & 20,0 & 25.854 & 6,3 & 29.116 & 7,1 & 1.103 & 0,3 & 407.647 \\
1991 & 180.735 & 50,1 & 83.151 & 23,1 & 63.054 & 17,5 & 31.976 & 8,9 & 775 & 0,2 & 360.655 \\
1992 & 197.522 & 49,1 & 94.818 & 23,6 & 73.223 & 18,2 & 35.113 & 8,7 & 749 & 0,2 & 402.350 \\
1993 & 250.007 & 51,6 & 110.356 & 22,8 & 85.345 & 17,6 & 37.749 & 7,8 & 871 & 0,2 & 484.342 \\
\hline
\end{tabular}

Fuente: Dirección General de Migraciones. M. ${ }^{\circ}$ de Asuntos Sociales.

La observación de las estadísticas de extranjeros residentes en España nos permite trazar, a muy grandes rasgos, la evolución de las entradas 
de inmigrantes. Entre 1975 y 1993 la cifra total prácticamente se triplica ${ }^{2}$, al tiempo que se aprecian algunos cambios (cuadro 2). Considerados por continentes el peso de los europeos es mayoritario durante todo el periodo. Incluso cuando aparenta descender (1991) es debido a los cambios acaecidos por la consideración de los ciudadanos de la Unión Europea y por la diferente contabilidad a partir de esta fecha. Lo más destacable es, no obstante, el aumento de asiáticos y africanos, que se multiplican por 4 y por 26, respectivamente, mientras que los americanos, aunque duplican ampliamente sus efectivos, pierden peso proporcional en el conjunto y lo hacen, sobre todo, por pérdida de importancia de los procedentes de América Latina.

\section{LOS NUEVOS FLUJOS. LA APERTURA AL ESTE}

La inmigración europea ha sido siempre, y es, la que presenta un mayor peso en el total. Ahora bien, haciendo abstracción del conjunto de los procedentes de los países miembros de la Unión Europea, que desde 1991 dejan de considerarse en las estadísticas, el análisis de los grupos más importantes de extranjeros solicitantes de permisos de trabajo, por país de origen, presenta una evolución en la que destaca el descenso comparativo de algunas nacionalidades (principalmente estadounidense), frente al ascenso de otras. De éstas, es especialmente notable el caso de Marruecos, que aumenta en 26,9 su proporción en el total de extranjeros residentes en España, seguida de Perú y República Dominicana con cerca de 4 (cuadro 3). Hay un tercer grupo que merece una especial consideración por diversas razones. Es el flujo que procede de los llamados paises del Este, antiguos satélites de la URSS que, si bien no se puede considerar nuevo, sino muy al contrario, poseedor de una larga trayectoria emigratoria, tras el paréntesis de su etapa comunista, renueva la vieja corriente que ahora diversifica sus destinos. Entre éstos está España, donde, aunque no totalmente nuevo, sí que experimenta ahora un auge inusitado. En este flujo el papel protagonista lo tiene el grupo de polacos, cuya colonia es la más numerosa de todas las del Este, que llega a alcanzar en

En estas cifras hay que considerar que no es todo resultado del aumento. También ha tenido lugar en los últimos años un proceso de regularización que ha propiciado una mejor cobertura del registro de los extranjeros en España. Pese a todo, la clandestinidad es un fenómeno que sigue presente. 
España el noveno lugar entre las nacionalidades no comunitarias, según la Estadística de Residentes de 1993 (cuadro 4).

CUADRO 3. EVOLUCIÓN DEL VOLUMEN DE TRABAJADORES EXTRANJEROS EN ESPAÑA DE LAS PRINCIPALES NACIONALIDADES

\begin{tabular}{|c|c|c|c|c|c|}
\hline \multirow{2}{*}{ PAis } & \multicolumn{2}{|c|}{1989} & \multicolumn{2}{|c|}{1993} & \multirow[b]{2}{*}{$\Delta$} \\
\hline & TOTAL & $\%$ & TOTAL & $\%$ & \\
\hline Austria & 522 & 0,7 & 505 & 0,4 & $-0,3$ \\
\hline Noruega & 270 & 0,4 & 385 & 0,3 & $+0,1$ \\
\hline Suecia & 1.327 & 1,9 & 1.072 & 0,9 & $-1,0$ \\
\hline 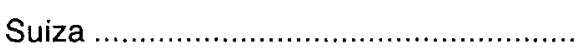 & 913 & 1,3 & 862 & 0,7 & $-0,6$ \\
\hline 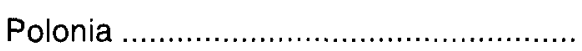 & 325 & 0,5 & 2.676 & 2,3 & $+1,8$ \\
\hline 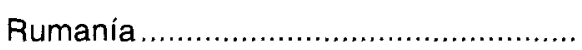 & 248 & 0,3 & 543 & 0,5 & $+0,2$ \\
\hline 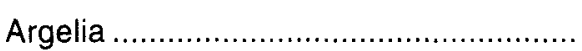 & 159 & 0,2 & 2.086 & 1,8 & $+1,6$ \\
\hline 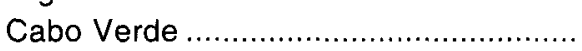 & 662 & 0,9 & 1.034 & 0,9 & 0,0 \\
\hline Gambia & 773 & 1,1 & 2.290 & 2,0 & $+0,9$ \\
\hline 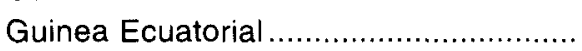 & 114 & 0,2 & 731 & 0,6 & $+0,4$ \\
\hline 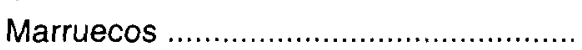 & 6.712 & 9,6 & 42.193 & 36,5 & $+26,9$ \\
\hline 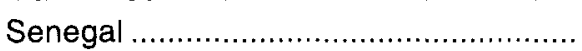 & - & - & 2.706 & 2,3 & $+2,3$ \\
\hline EE UU & $2.81 \overline{0}$ & $\overline{4}, 0$ & 2.513 & 2,2 & $-1,8$ \\
\hline 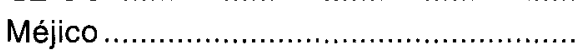 & 558 & 0,8 & 620 & 0,5 & $-0,3$ \\
\hline 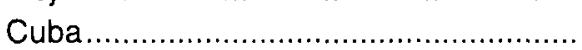 & 679 & 1,0 & 775 & 0,7 & $+0,3$ \\
\hline Rep. Dominicana & 528 & 0,7 & 5.211 & 4,5 & $+3,8$ \\
\hline Argentina & 4.342 & 6,2 & 8.941 & 7,7 & $+1,5$ \\
\hline 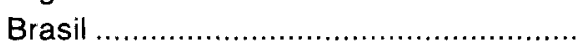 & 379 & 0,5 & 1.509 & 1,3 & $+0,8$ \\
\hline 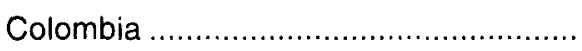 & 951 & 1,4 & 2.423 & 2,1 & $+0,7$ \\
\hline 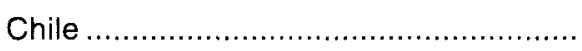 & 1.435 & 2,0 & 2.586 & 2,2 & $+0,2$ \\
\hline Perú & 689 & 1,0 & 6.088 & 5,3 & $+4,3$ \\
\hline 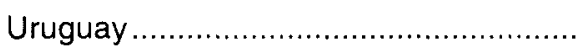 & 961 & 1,4 & 1.592 & 1,4 & 0,0 \\
\hline Venezuela ....................... & 1.247 & 1,8 & 993 & 0,9 & $-0,9$ \\
\hline 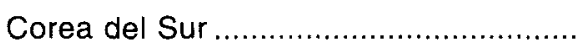 & 448 & 0,6 & 596 & 0,5 & $+0,1$ \\
\hline China & 1.373 & 2,0 & 4.789 & 4,1 & $+2,1$ \\
\hline 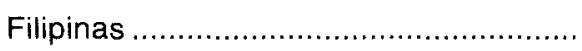 & 3.441 & 4,9 & 6.015 & 5,2 & $+0,3$ \\
\hline India & 1.710 & 2,4 & 2.125 & 1,8 & $-0,6$ \\
\hline Irán & 390 & 0,5 & 494 & 0,4 & $-0,1$ \\
\hline 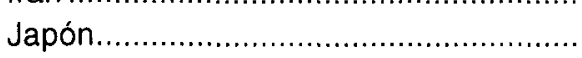 & 790 & 1,1 & 1.217 & 1,0 & $-0,1$ \\
\hline Pakistán & 287 & 0,4 & 628 & 0,5 & $+0,1$ \\
\hline TOTAL. & 69.907 & 49,8 & 115.437 & 91,5 & $+42,7$ \\
\hline
\end{tabular}

Fuente: $\mathrm{M}^{\circ}$ de Trabajo y Asuntos Sociales. 
CUADRO 4. PERMISOS DE TRABAJO CONCEDIDOS A CIUDADANOS DE PAISSES DEL ESTE DE EUROPA 1989-1994

\begin{tabular}{|c|c|c|c|c|c|c|}
\hline PAIS & 1989 & 1990 & 1991 & 1992 & 1993 & 1994 \\
\hline Albania (1)... & - & - & - & - & - & - \\
\hline Bulgaria ............. & 135 & 235 & 457 & 546 & 500 & 535 \\
\hline$C E \mid(1) \ldots \ldots \ldots \ldots$ & - & - & - & - & - & - \\
\hline Checoslovaquia.. & 192 & 327 & 472 & 521 & 489 & 439 \\
\hline Hungría.............. & 80 & 92 & 97 & 124 & 100 & 93 \\
\hline Polonia .. & 325 & 522 & 2.007 & 3.276 & 2.676 & 2.596 \\
\hline 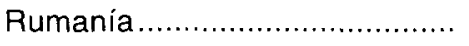 & 248 & 263 & 375 & 587 & 543 & 639 \\
\hline Yugoslavia Ex. (1) .................. & - & - & - & - & - & 510 \\
\hline TOTAL.... & 980 & 1.439 & 3.408 & 5.054 & 4.308 & 4.812 \\
\hline
\end{tabular}

(1) No disponemos de datos desagregados para estas nacionalidades.

Fuente: $\mathrm{M}^{\circ}{ }^{\circ}$ de Trabajo y Asuntos Sociales.

Las estadísticas del Ministerio de Trabajo no recogen la totalidad de los componentes de cada grupo, sino, tan sólo, los que solicitan permiso de trabajo, no obstante, son un indicador claro de la evolución del colectivo, que se multiplica por cinco en cinco años y que ha comenzado a hacerse visible y a que la sociedad vaya tomando conciencia de su existencia. En el conjunto de las migraciones actuales debe hacerse un apartado para el flujo que procede de los países del Este. Como resultado de la caída del muro de Berlín y de acontecimientos que se desarrollaron posteriormente, hubo una serie de cambios que hicieron presagiar una salida masiva de población que podría suponer una avalancha en los países occidentales. Este "temor" se justificaba con algunas razones, dado que los paises del Este poseen una larga tradición emigratoria, han pasado por un largo paréntesis de secuestro de libertades y, consiguientemente, de dificultad para salir del país. Se encontraban en una situación difícil (paro, industria obsoleta, exceso de mano de obra en la agricultura, etc.) y ante un futuro incierto. La realidad ha dejado estos presagios reducidos a su justo término y no se ha producido tal avalancha, sino tan sólo una salida importante. Esta salida, cuyos principales destinos son Alemania y otros países de Europa occidental y Norteamérica, como era previsible, llega también a España, donde destaca un grupo que supera el $54 \%$ del conjunto del Este, el de los polacos.

Este colectivo, que ha cobrado cierta importancia en el conjunto de la inmigración en España, presenta unas peculiaridades que afectan, entre 
otras, a la acogida que encuentran en nuestro país, que nos mueven a hacer algunas reflexiones.

\section{LA COLONIA POLACA ¿UN CASO DIFERENTE?}

\subsection{Posturas xenófobas en la sociedad occidental}

En los últimos años estamos asistiendo a un cierto renacer de posturas que se pueden considerar como de cierta xenofobia o racismo. Sin entrar de lleno en esta importante cuestión podemos, a modo de ejemplo, recordar cómo con frecuencia aparecen en la prensa noticias que relatan hechos marcadamente racistas y xenófobos, agresiones a personas de "aspecto» o "raza" distinta, a veces con resultado de muerte, expulsiones, situaciones de marginación, explotación y un largo etcétera. Muchas de estas noticias proceden del exterior, con frecuencia de países como Alemania, Austria o Francia, donde es muy elevado el número de inmigrantes, pero también son abundantes en un país como España, donde hace unos años la opinión mayoritaria de la población era que no existían los planteamientos racistas. En un análisis que realizamos de la encuesta llevada a cabo entre los españoles por el CIRES, respecto a las actitudes hacia los inmigrantes, destacábamos la existencia de una postura en cierto modo recelosa frente a la actual situación de España como receptor de inmigrantes (AGUILERA, M. J.; GONZÁLEZ-YANCI, M. P.; RODRÍGUEZ, V., 1993). Pese a que el número de extranjeros es muy bajo en relación con las cifras de los paises tradicionalmente receptores de Europa, para un $51 \%$ de los encuestados españoles, aquéllos ya resultaban muchos o demasiados. Predomina la opinión de que debería ponerse límite a la entrada de extranjeros, con un mayor rechazo hacia los norteafricanos, a los que se considera, junto a los africanos negros, con mayores dificultades para conseguir la integración, siendo los principales problemas para ello la diferencia racial y sobre todo cultural. No obstante hay que hacer muchas matizaciones, por ejemplo que en dichas opiniones hay claras diferencias según la edad y el nivel cultural de los encuestados, de modo que los españoles más jóvenes y los de mayor nivel cultural y social, son los más favorables a la acogida e integración de inmigrantes. De algún modo se desprende de la encuesta que, para determinados grupos, hay cierta preocupación por el nuevo fenómeno. 
Insistiendo en este punto no podemos olvidar el endurecimiento de las medidas legales sobre acogida de extranjeros, que han adquirido matices claramente restrictivos al aumentar las exigencias a cumplir (permiso de trabajo, certificado de residencia, visado...) y al limitar el número de acogidas. Desde 1993 mediante resolución de la Subsecretaría de Relaciones con las Cortes y de la Secretaría del Gobierno, se dictan instrucciones para la autorización de un contingente de trabajadores que podrían ser admitidos en el año (cupos).

Por otro lado, hay una opinión respecto a que existe un tipo de racismo, que podemos llamar "económico", que está relacionado no tanto con el color y rasgos físicos, ni con los caracteres culturales, sino, sobre todo, con un rechazo de la pobreza y tanto más cuanto más vaya acompañada de diferencias de carácter cultural y étnico, con lo que se agudiza.

En esta nueva situación en que está actualmente España encontramos que, precisamente el grupo de inmigrantes polacos se percibe de forma diferente a otros colectivos que, a priori, podrían considerarse semejantes.

\subsection{La inmigración polaca}

El caso de los polacos resulta un tanto particular. A través de un amplio y profundo estudio ${ }^{3}$ realizado con anterioridad, conocemos los principales rasgos que definen a esta colonia y que vamos a resumir para establecer la comparación con otros inmigrantes en España.

En sus inicios la débil corriente de polacos que acudia a nuestro país tuvo un carácter marcadamente político. Hubo un cierto número de personas, en buena medida pertenecientes a la nobleza, que acudian a España, donde la dictadura existente ofrecía fácil refugio frente a un régimen socialista. La implantación del comunismo en Polonia supuso un paréntesis en la tradicional salida de población del país, que contaba con un largo pasado y que fue especialmente notable en la segunda mitad del siglo XIX, cuando la fuerte presión demográfica, la escasez de empleo industrial y el exceso de población dedicada a la agricultura for-

\footnotetext{
3 Parte de los contenidos de este artículo están basados en un informe realizado conjuntamente con el doctor Rodríguez Rodriguez del CSIC para la Dirección General de Migraciones, en 1995.
} 
zaban a la salida, al igual que en otros países europeos. A pesar de todo, desde el inicio de la década de los años ochenta, hay en Polonia una reactivación de la emigración (que nunca cesó de forma clandestina, pese a las dificultades oficiales), que supuso la salida de más de un millón de personas durante la década. Las transformaciones ocurridas desde la caída del muro de Berlín, en 1989, abrieron una nueva etapa para la que algunos pronosticaron una salida masiva de ciudadanos de los países del Este, como antes comentamos. En estos años finales del comunismo es cuando se detecta en España un aumento de las solicitudes de asilo y refugio por parte de ciudadanos polacos. En los tres últimos años de la década fue la nacionalidad que ocupó el primer puesto entre los solicitantes de esta figura legal, con porcentajes de en torno al $40 \%$ del total de peticiones registradas. Según el Censo de 1991 el $94 \%$ de los polacos residentes en España habían llegado en esta década (cuadro 5).

CUADRO 5. LLEGADA A ESPAÑA DE LOS INMIGRANTES POLACOS

\begin{tabular}{|c|c|}
\hline AÑO DE LLEGADA & $\%$ \\
\hline 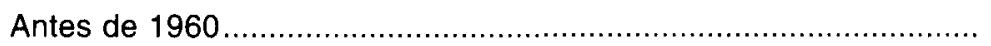 & 1,9 \\
\hline $1960-1970 \ldots \ldots \ldots \ldots \ldots$ & 1,7 \\
\hline 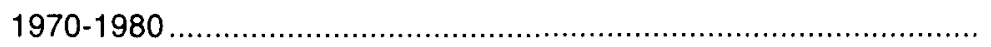 & 2,4 \\
\hline 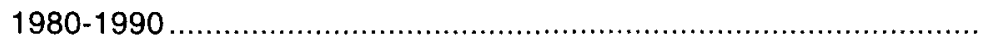 & 94,0 \\
\hline 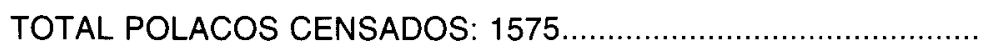 & 100,0 \\
\hline
\end{tabular}

Fuente: Censo de la Población de España de 1991.

Por tanto, se trata de una inmigración reciente, en la que en principio predomina el carácter político, o al menos el sentimiento de los inmigrantes de tener ante todo una motivación política. Está compuesta por un número que se calcula puede superar las 10.000 personas, ahora bien, conocer con exactitud la cifra es sumamente complejo, como ocurre con la mayoría de las colonias de extranjeros. Las fuentes a partir de las que se pueden estudiar son diversas, pero resultan muy incompletas, ya que cada una, por sus propias características, recoge parte del total y además no son excluyentes entre sí. El cuadro 6 muestra las diferencias que existen. Por ejemplo, mientras que en el Censo de 1991, que es, en principio, la fuente más universal, la cifra era de 1.575 , en ese mismo año solicitaron ser regularizados 3.459 trabajadores más 423 familiares. 
CUADRO 6. POBLACIÓN POLACA EN ESPAÑA SEGÚN LAS DISTINTAS FUENTES

\begin{tabular}{lccccccc}
\hline \multicolumn{1}{c}{ FUENTE } & 1988 & 1989 & 1990 & 1991 & 1992 & 1993 & 1994 \\
\hline Censo de España........ & - & - & - & 1.575 & - & - & - \\
Censo de CAM ........... & - & - & - & 1.004 & - & - & - \\
Exp. Regularización .... & - & - & - & 3.882 & - & - & - \\
Per. Trab. Concedidos & - & 325 & 522 & 2.007 & 3.276 & 2.692 & 2.596 \\
Soli. Asilo-Refugio....... & 2.086 & 1.723 & 2.937 & 972 & 1.190 & 602 & - \\
DGM Residentes......... & - & - & - & - & - & 4.163 & - \\
CRE* Atenciones........ & - & 2.432 & 3.519 & 1.864 & - & - & - \\
\hline
\end{tabular}

Fuente: Elaboración propia.

* Cruz Roja Española.

Veamos, a continuación, las principales características del grupo de polacos. En primer lugar la distribución espacial que presentan, analizada a partir de las estadisticas del proceso de regularización y permisos de trabajo, resulta muy similar a la del conjunto de la inmigración extranjera. La mayor parte se concentra en Madrid y área de influencia central (Segovia, Guadalajara, Toledo y Ávila). Hay además otros grupos destacables en las provincias mediterráneas (Barcelona, Tarragona y Comunidad Valenciana) y en las de tradición industrial (Asturias, Vizcaya y Guipúzcoa). Como es natural, las áreas de atracción son las mismas para todos los inmigrantes. De un lado la capital y grandes ciudades y de otro las zonas de más pujanza económica, que al ser más dinámicas generan mayor oferta de puestos de trabajo, tanto en los servicios, como en la construcción o industria e, incluso, en el sector agrario más rico. Las diferencias suelen estar en la proporción en que está cada grupo, así en todos los casos suele ser considerable el porcentaje de inmigrantes que están en la capital, pero entre los africanos hay además importantes grupos en zonas agrarias de levante y los portugueses son más numerosos en el oeste. Lo más destacable, en el caso de los polacos, es su presencia en zonas industriales, hecho poco frecuente entre los inmigrantes del mundo en desarrollo (figura 1).

Su distribución espacial en España no difiere mucho de la que tienen en origen, que ayuda a explicar las razones que impulsan a esta población a emigrar. La figura 2 muestra que la mayoría de los emigrantes polacos proceden de las demarcaciones (llamadas voivodias) del sureste del país, 
precisamente las de carácter más rural, seguidas de las principales ciudades y de la región industrial del norte ${ }^{4}$.

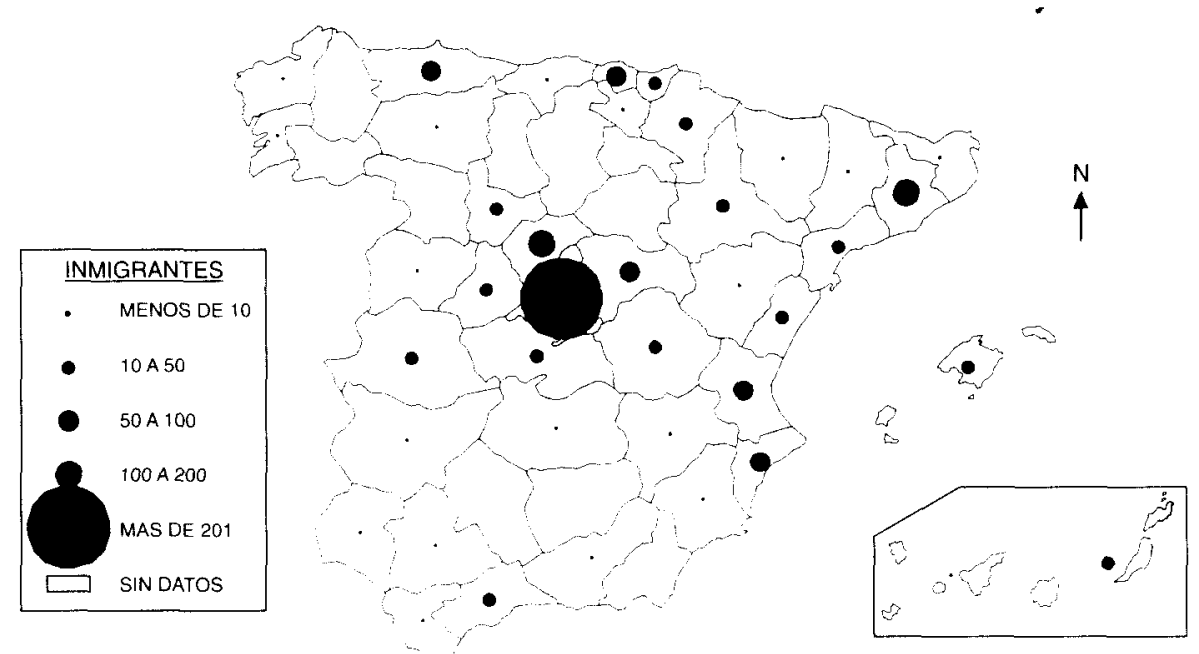

Fuente: Ministerio de Trabajo y S.S. Elaboración propia.

Figura 1. Distribución de los inmigrantes polacos en 1992 (permisos de trabajo).

Desde el punto de vista demográfico, la colonia polaca tiene un predominio de varones, aunque no llega a alcanzar el desequilibrio entre los sexos que se da en otros grupos de inmigrantes, en especial de los procedentes del mundo menos desarrollado. Los varones suponen el $57 \%$ del total. Es, por otro lado, un grupo joven, cuyos más abundantes efectivos se concentran entre los 20 y 34 años, donde los ancianos son escasos $y$, en cambio, los niños son relativamente numerosos en relación a otras colonias, aunque menos de lo que correspondería a tan nutrido número de jóvenes, pero suficientes como indicio de una presencia familiar (figura 3). Estos datos proceden del Censo de Población, que no contempla a todo el colectivo, sino al conjunto más asentado y con mayor proporción de familias reunidas. En la misma fecha las solicitudes de regularización y los

4 Es de gran dificultad obtener el dato del lugar de procedencia de los inmigrantes dentro de su país. Sólo es posible a través de la información consular, a la que no siempre se tiene acceso. En el caso de Polonia pudimos obtener esta valiosa información para 982 inmigrantes, con la que se elaboró el mapa de la figura 2. 


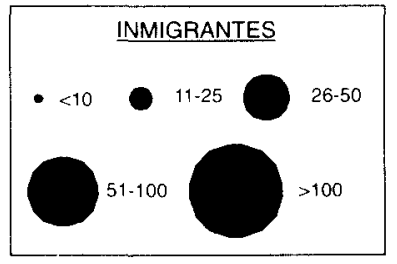

1. SZCZECIN

2. GORZOW

3. ZIELONA GORA

4. LEGNICA

5. JELENIA GORA

6. KOSZALIN

7. SLUPSK

8. PILA

9. POZNAN

10. LESZNO

11. KALISZ

12. WROCLAW

13. OPOLE

14. GDANSK

15. ELBLAG

16. BYDGOSZCZ

17. TORUN

18. WLOCLAWEK

19. PLOCK

20. KONIN

21. SIERADZ
22. LODZ

23. SKIERNIEWICE

24. PIOTRKOW TR.

25. CZESTOCHOWA

26. KATOWICE

27. KRAKOW

28. BIELSKO BIALA

29. OLSZTYN

30. CIECHANOW

31. OSTROLEKA

32. WARSZAWA

33. RADOW

34. KIELCE

35. TARNOW

36. NOWY SACZ

37. SUWALKI

38. LOMZA

39. BIALYSTOK

40. SIEDLCE

41. BIALA PODLASKA

42. LUBLIN

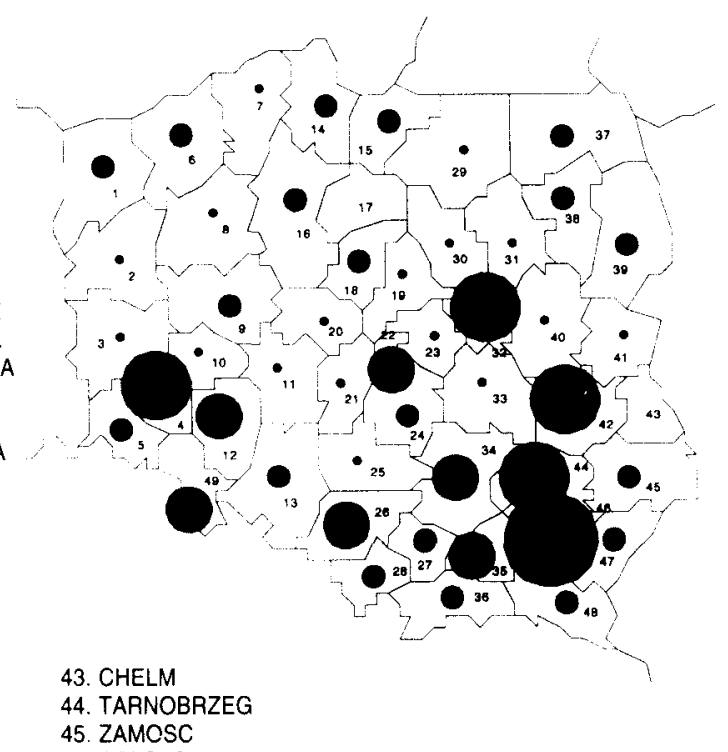

45. ZAMOSC

46. RZESZOW

47. PRZEMYSL

48. KROSNO

49. WALBRZYCH
Fuente: Registro del Consulado de Polonia.

Elaboración propia.

Figura 2. Procedencia de los inmigrantes polacos en España, 1993.

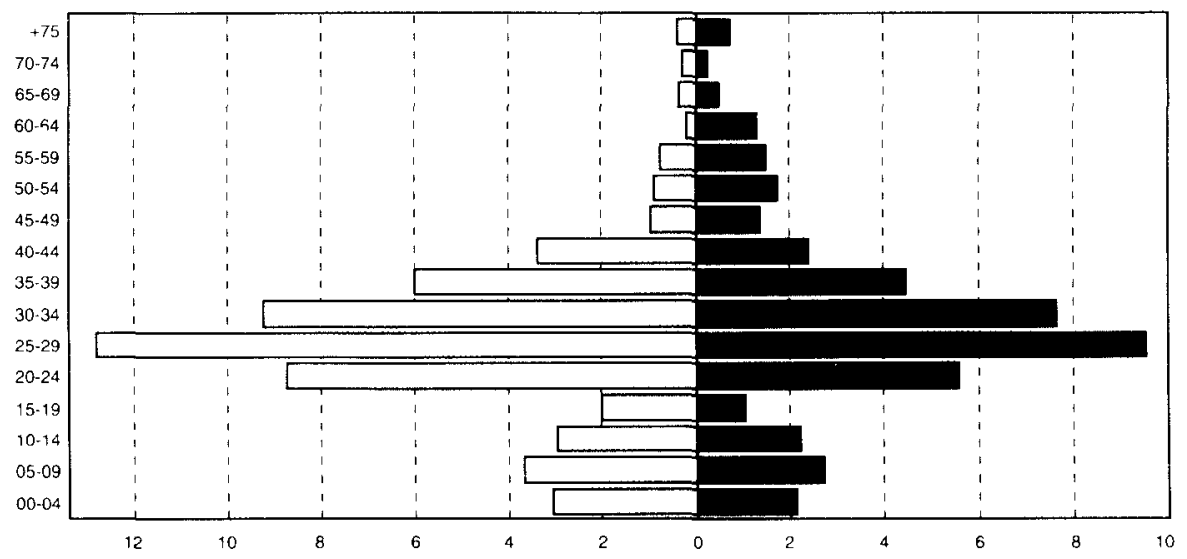

Fuente: Censo de la Población de España, 1991. Tomado de: Lora-Tamayo, G. (1995). "Características de la Población Extranjera en España». ASTI, p. 45.

Figura 3. Pirámide de población de la colonia polaca en España. 
permisos de trabajo presentan una mayoría de varones mucho más acusada (cerca del $77 \%$ en ambos casos) (figura 4), lo que parece indicar el carácter más "económico" de los inmigrantes registrados en este proceso, que comprende fundamentalmente a los últimos llegados. Aunque entre los más asentados la proporción es de 1,5 varones por mujer, en el conjunto la proporción llega a ser de 3 a 1.

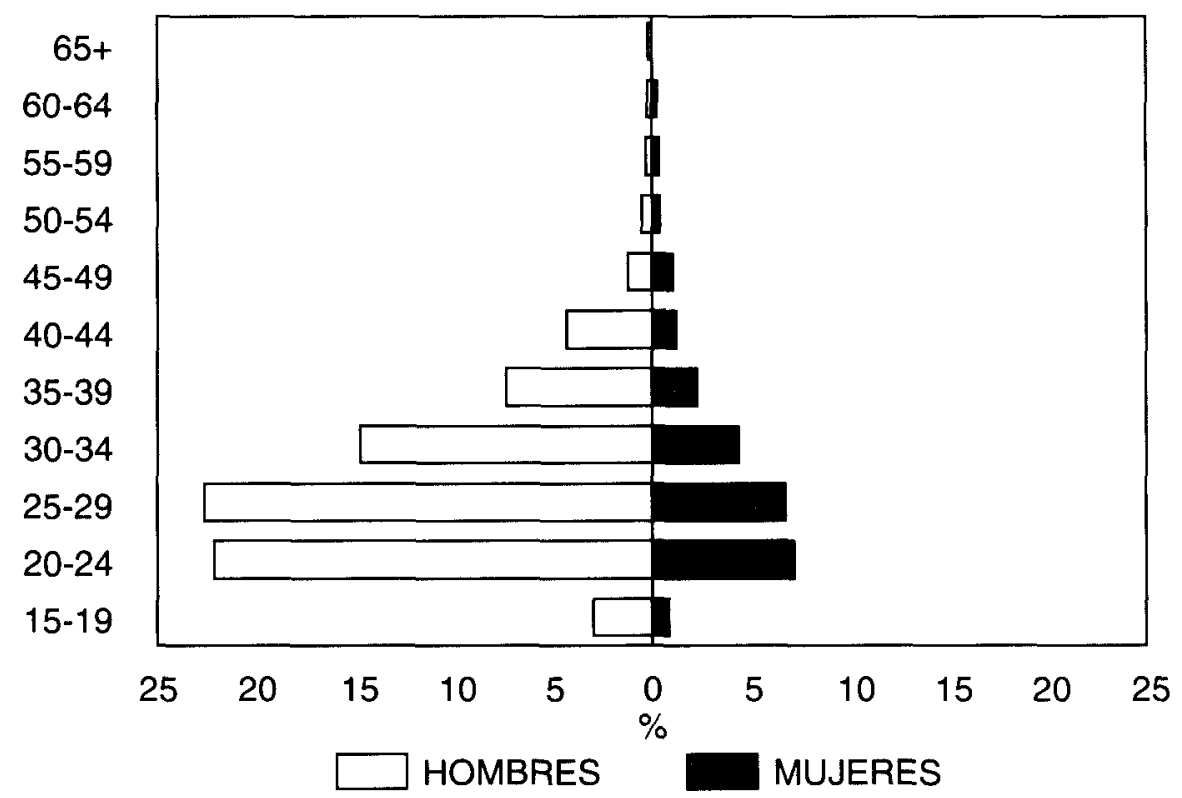

Fuente: DGM. Proceso de Regularización 1991.

Elaboración propia.

Figura 4. Pirámide de población de los inmigrantes polacos en España. Proceso de regularización de 1991.

Las variables de tipo económico son, sin lugar a dudas, más significativas. La población polaca muestra aquí, todavía más, la dicotomía que se intuye en los rasgos demográficos entre el grupo más antiguo y asentado y los más recientemente llegados. La tasa de actividad global, calculada a partir de los datos censales, es una de las más elevadas de entre todas las colonias de extranjeros $(50,4 \%)$ siendo la de los varones el $61,7 \%$ y la de las mujeres el $35,5 \%$. Sin embargo, también esta colonia es la que presenta mayor tasa de paro $(33,5)$, correspondiendo el $20,9 \%$ al paro masculino y el $11,7 \%$ al femenino. En cambio la situación de los po- 
lacos es un tanto precaria, ya que el $46,7 \%$ de los trabajadores son asalariados eventuales, proporción sólo superada por la colonia marroqui, aunque en consonancia con la situación laboral del país.

Los polacos realizan su trabajo fundamentalmente en actividades pertenecientes al sector servicios. Todas las fuentes analizadas nos brindan proporciones superiores al $50 \%$ en dicho sector (cuadro 7 ). Le sigue el de la construcción, que concentra la cuarta parte de los activos, siendo mucho menos numerosos los trabajadores dedicados a la industria (que no obstante en algunos lugares, como la Comunidad de Madrid alcanzan un $19 \%$ ) y los agrarios que tienen proporciones muy reducidas, sobre todo en comparación con otros colectivos de inmigrantes, como los africanos.

\begin{tabular}{|c|c|c|c|c|}
\hline $\begin{array}{l}\text { SECTOR } \\
\text { ACTIVIDAD }\end{array}$ & $\begin{array}{l}\text { P.T. CONCED. } \\
\text { ANNO } 1992(\%) \\
N=3.276\end{array}$ & $\begin{array}{c}\text { REGULARI- } \\
\text { ZADOS } 1991(\%) \\
\mathrm{N}=3.328\end{array}$ & $\begin{array}{l}\text { CEN. POBLAC. } \\
\text { CAM } 1991(\%) \\
N=1.004\end{array}$ & $\begin{array}{c}\text { CEN. POBLAC. } \\
\text { ESPAÑA } 1991(\%) \\
N=1.575\end{array}$ \\
\hline Agrario .................... & 2,7 & 3,7 & 0,5 & 2,3 \\
\hline Industrial............. & 12,0 & 12,2 & 19,0 & 12,3 \\
\hline Construcción .... & 31,2 & 31,9 & 25,0 & 23,0 \\
\hline Servicios............... & 53,6 & 52,2 & 55,5 & 52,4 \\
\hline
\end{tabular}

Fuente: Ministerio de Trabajo y Asuntos Sociales. INE.

Respecto a la profesión declarada se aprecia una marcada dualidad. Se concentran en dos grupos, el más numeroso, según los expedientes del proceso de regularización, es el de los trabajadores de la industria y la construcción $(47,8 \%)$, y los trabajadores de servicios personales, de hostelería, y domésticos $(30,3 \%)$. En el otro extremo de la escala se hallan los profesionales y administrativos (10\%), siendo los restantes grupos mucho menos numerosos. Similar dicotomía se aprecia en los datos del censo, aunque con algunos matices. En este caso los profesionales, técnicos y similares, profesiones más valoradas, son muy numerosos $(28,7 \%)$. Los trabajadores en construcción, industria, minería y transportes suponen el $30,2 \%$, constituyendo junto a los peones y trabajadores no especializados $(10,2 \%)$ el otro extremo de la escala laboral. Es de destacar, además, el hecho de que existan unas diferencias notables por sexo, que comentamos por su significado en relación a otros colectivos de inmigrantes. En este caso, las mujeres presentan una importante proporción de profesionales y técnicas $(35,6 \%)$, siendo también numerosas las que trabajan en 
servicios personales $(44,8 \%)$. A partir del censo podemos establecer la comparación con otras nacionalidades. Se observa que, en lo referente a la profesión, los polacos presentan ciertas semejanzas con los procedentes del mundo desarrollado, al tener proporciones en el grupo de profesionales, técnicos y similares, más próximas a las de aquéllos que las que presentan los países menos desarrollados. En cambio, se asemejan más a estos últimos en cuanto a que tienen porcentajes muy elevados de ocupados en las escalas inferiores, peones y trabajadores de la construcción, industria y minería.

De todo lo visto hasta aqui parece deducirse que en el caso de Polonia hay una dualidad, que sitúa a este pais en una posición intermedia entre los mundos desarrollado y subdesarrollado. El cuadro que establece la comparación de algunos indicadores entre España, Marruecos y Polonia resulta expresivo en este sentido, mostrando la existencia de semejanzas claras entre Polonia y España en algunos aspectos (natalidad, crecimiento...), con Marruecos en otros, sobre todo económicos (renta per cápita) y una posición intermedia en los restantes (cuadro 8). No obstante, podemos afirmar que en la actualidad los polacos en España constituyen un grupo de inmigrantes económicos que, aunque se asemejan a los españoles en muchos rasgos y están cercanos a los colectivos de países occidentales, perdida ya su característica de refugiados, acuden a nuestro país en pie de igualdad con grupos de inmigrantes procedentes del mundo en desarrollo con los que compiten en trabajos de bajo nivel.

\subsection{La acogida de los polacos en España}

A pesar de las semejanzas que acabamos de ver con la mayoría de los grupos de inmigrantes que llamamos "económicos", y de la constatación de la existencia de ciertos brotes xenófobos en la sociedad, llama la atención la diferente acogida que encuentra la población polaca entre los españoles si la comparamos con la de otros grupos. Las razones de este hecho son múltiples y variadas. Como ya indicábamos anteriormente se trata de un grupo cuya antigua migración comienza siendo de refugiados políticos. Los más antiguos, que coinciden con los registrados en el censo, presentan características parecidas a las de los europeos occidentales, sin embargo los que llegan después de 1990, aunque pretendieron acogerse al estatuto de asilo y refugio, coinciden más bien con los inmigrantes que llamamos "económicos", siendo los que aparecen en las estadísticas de permisos de trabajo y expedientes de regularización. Éstos son, 
además, más numerosos y por ello podríamos pensar que pesaran más en la acogida que les dispensaran los españoles, similar a la de los grupos meramente económicos de la inmigración reciente. Partimos, por tanto, de la existencia de dos grupos con un cierto contraste dentro del colectivo, en cambio el primero y menos numeroso de ellos es el que parece tener más peso en la opinión que los españoles se han formado del conjunto.

CUADRO 8. COMPARACIÓN DE LAS CARACTERÍSTICAS DE ESPAÑA, POLONIA Y MARRUECOS

\begin{tabular}{|c|c|c|c|c|c|c|}
\hline \multirow{2}{*}{ INDICADORES } & \multicolumn{3}{|c|}{1993} & \multicolumn{3}{|c|}{1995} \\
\hline & ESPAÑA & POLONIA & MARRUECOS & ESPAÑA & POLONIA & MARRUECOS \\
\hline Población mitad año (millones) ........ & 39,1 & 38,5 & 28,0 & 39,1 & 38,6 & 29,2 \\
\hline 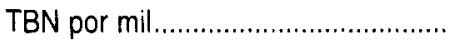 & 10 & 13 & 31 & 10 & 12 & 28 \\
\hline 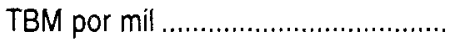 & 9 & 10 & 8 & 9 & 10 & 6 \\
\hline Crecimiento anual $(\%)$ & 0,1 & 0,3 & 2,4 & 0,1 & 0,2 & 2,2 \\
\hline Años duplicación población .............. & 578 & 224 & 29 & 578 & 301 & 32 \\
\hline Proyección población $2010 \ldots \ldots \ldots \ldots . .$. & 38,9 & 41,3 & 38,1 & 39,0 & 40,2 & 38,4 \\
\hline Proyección población $2025 \ldots \ldots \ldots \ldots \ldots . . . .$. & 36,4 & 42,7 & 46,3 & 37,1 & 41,7 & 47,4 \\
\hline 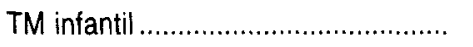 & 7,8 & 14,4 & 57 & 7,6 & 13,7 & 57 \\
\hline Tasa de fertilidad .................................. & 1,3 & 2,0 & 4,2 & 1,2 & 1,8 & 4,0 \\
\hline \% jóvenes < 15 & 19 & 25 & 40 & 17 & 24 & 40 \\
\hline$\%$ ancianos $>65 \ldots \ldots \ldots \ldots \ldots \ldots \ldots$ & 14 & 10 & 4 & 15 & 11 & 4 \\
\hline Esperanza de vida en años (total)... & 77 & 71 & 65 & 77 & 72 & 69 \\
\hline Esperanza de vida en años $\mathrm{H} / \mathrm{M} \ldots . . .$. & $73 / 70$ & $67 / 76$ & $64 / 67$ & $73 / 81$ & $67 / 76$ & $67 / 71$ \\
\hline 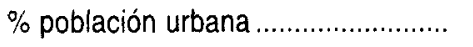 & 78 & 62 & 47 & 64 & 62 & 47 \\
\hline Renta per cápita \$ USA ................... 1 & 12.460 & 1.830 & 1.030 & 3.650 & 2.270 & 1.030 \\
\hline
\end{tabular}

Fuente: Population Reference Bureau Inc. USA, 1993-1995.

A partir de los datos censales podemos conocer el nivel de estudios de este primer grupo, donde, desde nuestro punto de vista, radica parte de la opinión favorable a que aludimos. El nivel educativo resulta más elevado que el de la mayoría de las colonias de extranjeros y desde luego mayor que el de todos los procedentes del mundo en desarrollo. Analizando los datos resulta que es muy pequeño el número de analfabetos $(0,5 \% \mathrm{com}$ parable al de los estadounidenses, frente a un $12,7 \%$ de los marroquíes) y $\sin$ estudios $(5,7 \%$, similar a los suizos, frente al $34 \%$ de los marroquies). Mientras que la proporción de polacos de más de 10 años con estudios medios y superiores es de $30 \%$ equiparable a la de los suizos o estadounidenses frente al $4,7 \%$ de los marroquíes. Resulta ser la colonia que 
ocupa el tercer lugar por su nivel de instrucción del conjunto de los extranjeros registrados en el censo, ocupando ese mismo puesto si se considera exclusivamente a las mujeres con titulación universitaria, lo que es aún más significativo. La semejanza en el nivel de formación con los países más avanzados del mundo occidental ha resultado beneficiosa en la formación de la imagen que los españoles se han forjado de los polacos.

A todo ello se suman también otras razones. Existe una cierta identidad cultural basada, entre otras cosas, en la generalizada pertenencia a la religión católica (incluso puede influir el hecho de que el Papa sea de la misma nacionalidad). Además por su aspecto no se hacen «visibles" a la población. Al consultar a un amplio grupo de españoles sobre los polacos, hemos observado que es bastante generalizada la opinión de que son discretos, trabajadores, estrictos cumplidores de la legislación y con gran facilidad y voluntad de integrarse en nuestra sociedad. A pesar de la grave dificultad que supone la diferencia lingüística, denotan una gran voluntad de salvarla, acudiendo a clases de español, que ellos mismos organizan. No suelen aparecer en los medios de difusión noticias negativas respecto a los comportamientos del grupo, a pesar de que no salen bien parados en la estadística de la Dirección General de la Policía, e, incluso, ellos mismos demuestran que se sienten bien acogidos, tanto cuando lo manifiestan directamente, como cuando, indirectamente, a través de los anuncios de prensa con los que solicitan empleo, no dudan en indicar como primera palabra su nacionalidad, de lo que es fácilmente deducible que se sienten valorados.

\section{CONCLUSIÓN}

No se puede negar que existen brotes de cierta xenofobia en la sociedad española actual, pero se deben hacer muchas matizaciones. Los rasgos étnicos influyen notablemente, pero no todos del mismo modo. La situación económica también juega un papel muy importante, incluso muchas veces es el auténtico motivo de rechazo, pero, si ambos aspectos étnicos y económicos se suman, el rechazo social puede ser mucho más acentuado.

En la percepción por una sociedad de los inmigrantes hay muchos elementos que condicionan su aceptación o su rechazo. El caso de los polacos es un buen ejemplo de la importancia de aspectos que como la semejanza cultural, o un elevado nivel de formación, tienen en la aceptación 
de la sociedad que los acoge, por encima de otros como la situación económica, que es en cambio dominante en muchas ocasiones.

\section{BIBLIOGRAFIA}

Aguilera, M. J.; González-Yanci, M. P., y Rodríguez, V. (1993): “Actitudes de la población española ante los inmigrantes extranjeros", Estudios Geográficos LIV, 210, pp. 145-154.

Aguilera, M. J.; Gonzalez-Yancl, M. P.; Pumares, P., y Rodriguez, V. (1995) «Investigación sobre la inserción laboral de los inmigrantes marroquies y polacos en España". Proyecto de investigación subvencionado por la Dirección General de Migraciones (Ministerio de Asuntos Sociales) a través de la Fundación Largo Caballero (inédito).

Aguilera, M. J.; GonzAlez-Yanci, M.P., y Rodriguez, V. (1996): "La nouvelle inmigration polonaise en Espagne», Revue Européenne des Migrations Internationales. Volume 12, $n .^{\circ} 91$, pp. 91-107.

ARAGÓN, R., y ChOZAS, J. (1993): "La regularización de inmigrantes 1991-1992", Madrid, Ministerio de Trabajo y Seguridad Social.

BELL, C. (1990): “Extranjeros en España (II). Refugiados: una aproximación al tema», Papeles de Geografía, 16, pp. 101-112.

Berlin, B. (1994): «Polacos: integrados y católicos", Rev. Carta de España, n. 478.

COLECTIVO IOE (1987): "Los inmigrantes en España», Documentación Social, n. ${ }^{\circ} 66$. Madrid.

DiEz NicolAS, J.(1992): “Los españoles ante la inmigración», Alfoz n. 91-92, pp. 71-77.

GozÁlVEz PEREZ, V. (1990): "El reciente inaremento de la población extranjera en España y su incidencia laboral», investigaciones Geográficas, n. ${ }^{\circ} 8$, pp. 7-36.

INSTITUTO ESPAÑOL DE EMIGRACIÓN (1990): "La inmigración en España. Panorama de una década 1980-1989", Madrid, Ministerio de Trabajo y Seguridad Social.

IZQUiERdo Escribano, A. (1992): " La inmigración en España, 1980-1990". Madrid, Ministerio de Trabajo y Seguridad Social.

LOPEZ LERA, D. (1994): “¿Quiénes son los extranjeros que viven en Madrid?". Economia y Sociedad, n. ${ }^{\circ} 10$, junio, pp. 103-117.

LoRA-TAmayo, G. (1995): “Características de la población extranjera en España». Censo de 1991. Cuadernos de Formación n. ${ }^{\circ}$, ASTI. Madrid, $67 \mathrm{pp}$.

Martin Seraano, M. (1993): "Los efectos sociales de la política inmigratoria", Política y Sociedad, n.: 12, pp. 37-43.

Mluñoz Pérez, F.; IzQuierdo, A. (1989): “L'Espagne, pays d'immigration», Population, n. ${ }^{\circ} 2, \mathrm{pp}$. 257-289.

OCHOA, C.(1993): "La inmimgración hacia España de los naturales de países terceros a la CEE: un nuevo fenómeno", Política y Sociedad, n. ${ }^{\circ} 12, \mathrm{pp}$. 97-120.

SALT, J. (1993): “External international migration" en NOIN y WOODS: The changing Population of Europe. London, Blackwel, pp. 185-197. 